\title{
The impact of a hospital audit on psychiatrists' letters to general practitioners
}

\author{
Premal J. Shah and lan Pullen
}

\begin{abstract}
The quality of wittien communication between poychiatrists and general practitioners has become increasingly important, with the introduction of the Access to Health Records Act as well as with demands placed by the purchasers of psychiatic services. We investigated if a hospltal-based audit could be used to monitor the quallity of witten communications with general practitioners, and if 'closing the oudit loop' could improve the standards. We found that audit may have helped improve standards, particularty in making letters less potentially offenstve and easier to read by non-poychicitists. A method of measuring the quallty of letters is described.
\end{abstract}

Good communication is essential for the effective management of out-patients. Although the opportunities for psychiatrists and general practitioners (GPs) to meet face to face is increasing (Pullen \& Yellowlees, 1985), most communication is still by letter (Margo, 1982) and is particularly important in psychiatry because of the complexity of many of the problems and since much of the service is out-patient based. Despite this, and the opinion that lack of training in communication skills such as letter-writing produces incompletely trained medical personnel (Young et al, 1991), these skills are seldom taught in medical curricula. An exception may be seen within the postgraduate education course at the Edinburgh Department of Psychiatry, where, for the past seven years, a session on letter-writing skills has been included.

The spectre of legislation granting patients access to their medical records was greeted with concern by many doctors on both sides of the Atlantic, and in Britain the Royal College of Psychiatrists opposed the Bill (Priest, 1986). Opponents of the legislation predicted that doctors would be inhibited from committing themselves on paper and the quality of medical case-notes would decline. Supporters of the changes suggested that case-notes would become more accurate.

Deficiencies in written communication will be more obvious to patients who read their own notes following the introduction of the Access to Health Records Act (1990) on 1st November 1991. A recent study (Crichton et al, 1992), for example, suggested that most psychiatric case-notes contained "at least one moderately or extremely offensive comment". Concerns regarding the implications of the Act for psychiatry prompted the Royal College of Psychiatrists (1992) to issue guidelines, emphasising the need to organise information effectively and suggesting case-note audit to evaluate 'inappropriate' and inaccurate information including 'offensive pejorative comments'.

Prompted by the Act, we performed an audit with two objectives: to evaluate the impact of the Act on the quality of written communication between psychiatrists and GPs, and to assess the impact of hospital audit meetings on letter-writing.

\section{The study}

One hundred and eighty letters written by general psychiatrists in the City of Edinburgh following out-patient assessment were studied.

\section{The sample}

This comprised letters written in response to 60 consecutive referrals from lst November 1990, 60 from 1st November 1991, and 60 from lst November 1992. These time periods were chosen to represent one year prior to, immediately following, and one year after the implementation of the Act. 
Letters were photocopied from case-notes and all identifying details (the patient's name and address, GP and psychiatrist, and date of referral) were removed. These letters were then rated blind by a consultant psychiatrist (IP).

\section{Standards set and parameters measured}

The directorate's standards for letters had been agreed in 1991 (C. Freeman, unpublished, 1991), incorporating the requirements of the Act, the 'key items' of information required by GPs and the 'ideal' format of letters as described previously (Yellowlees \& Pullen, 1984; Pullen \& Yellowlees, 1985). Letters were assessed for structure, content, and the presence of information from third parties and its clear demarcation; 'jargon'; value judgements and personal comments. Definitions of the above terms are included in the Appendix.

Because of the subjective nature of what constitutes a value judgement, personal comment or offensive pejorative remark, a sample of 20 letters was independently assessed by the main rater and a psychiatric registrar (DM). The results were then discussed by the three psychiatrists to arrive at a consensus, before the other letters were evaluated.

\section{Audit activity}

Guidelines were issued to all medical staff at a special meeting one month prior to the implementation of the Act. In May 1992 results of the surveys of letters written from November 1990 and November 1991 were presented to the hospital audit meeting and the standards were again agreed.

\section{Findings}

\section{Structure of letters and key information}

Overall, the structure of letters and the number of 'key items' of information have not changed over the three years. Fifty per cent of letters in both 1990 and 1991 and $70 \%$ in 1992 had headings. Letters ranged from a few lines to four sides of A4 paper, and since type size was uniform, comparing letter lengths was possible. There was no change in average letter length over the three years (mean $=25.3 \mathrm{~cm}$ ). Almost half (33/69) of the 69 letters written by trainees (senior house officers (SHOs) or registrars) were more than one page $(30 \mathrm{~cm}$ of text) in length compared to only nine of the 67 letters written by consultants.

Although the average number of 'key items' per letter (maximum=5) did not change significantly between 1990 (3.2 per letter), 1991 (3.1 items) and 1992 (3.25 items), more letters did provide a concise explanation of the patient's illness in 1992 than in $1990(65 \%$ of letters v. $\left.35 \%, \chi^{2}=9.6, P<0.05\right)$, but fewer gave prognostic information in 1992 than in 1990 ( $2 \%$ v. $18 \%$ of letters, $\chi^{2}=7.5, P<0.05$ ).

\section{Third party information}

Only six of the 180 letters (3\%) contained information from a third party, which was clearly demarcated in five. None of the six letters was from 1992.

\section{Presence of 'jargon' and 'value judgements/personal comments'}

Jargon There were significantly fewer letters containing jargon in 1992 (after audit activity) than 1991 (Table 1). There was no change between 1990 and 1991. Fewer letters written by consultants in 1991 contained jargon compared to letters written by other grades $\left(\chi^{2}=11.77, P<0.05\right)$, but this difference had disappeared by 1992.

Value judgements There were fewer letters from $1992(10 \%)$ than in $1991(23 \%)$ containing value judgements, although there was no change between 1990 and 1991.

Irrespective of the year, fewer consultants' letters contained jargon (31\% of consultants' letters c.f. $65 \%$ of all other letters) and value judgements $(17 \%$ of consultants' letters c.f. $34 \%$ of other letters), than letters written by other grades of staff.

Table 1. Presence of 'jargon' and 'value judgements/personal comments' in 180 psychiatrists' letters

\begin{tabular}{llll}
\hline & \multicolumn{3}{l}{ Number of letters (\%) } \\
\cline { 2 - 4 } & 1990 & 1991 & 1992 \\
& $n=60$ & $n=60$ & $n=60$ \\
\hline Jargon & $36(60)$ & $29(48)^{\circ}$ & $8(13)^{\circ}$ \\
Value judgements & $18(30)$ & $14(23)^{\mathrm{b}}$ & $6(10)^{\mathrm{b}}$ \\
\hline
\end{tabular}

${ }^{a} \chi^{2}=15.6, P<0.05 ;{ }^{b} \chi^{2}=4.8, P<0.05$. 
Table 2. Presence of value judgements in psychiatrists' letters according to letter length

\begin{tabular}{llll}
\hline & \multicolumn{3}{l}{ Letters with value judgements $(\%)$} \\
\cline { 2 - 4 } $\begin{array}{l}>1 \text { page } \\
(30 \mathrm{~cm}) \text { long }\end{array}$ & $\begin{array}{l}<1 \text { page } \\
\text { long }\end{array}$ \\
\hline $1990 / 91$ & $57 \%$ & $14 \%$ & $\left(\chi^{2}=12.6, P<0.05\right)$ \\
1992 & $27 \%$ & $4.5 \%$ & $\left(\chi^{2}=4.0, P<0.05\right)$ \\
\hline
\end{tabular}

Relationship to length of letter Letters longer than one page in length were more likely to contain value judgements than shorter ones (Table 2), regardless of the year in which they were written. Although there were fewer letters with value judgements in 1992, the relationship to letter length remained.

\section{Comment}

Medical audit has been defined as "the systematic, critical analysis of the quality of medical care, including the procedures for diagnosis and treatment, the use of resources, and the resulting outcome for the patient" (Department of Health, 1989). This involves a sequence of separate activities linked to form a loop, repeated as necessary (Open Forum, Education Committee, 1991). This paper reports one completed audit cycle. Standards were set based on the Act (1990) and previous Edinburgh studies (Yellowlees \& Pullen, 1984; Pullen \& Yellowlees, 1985). The College guidelines were only published one year after the implementation of the Act.

Although there is a teaching session devoted to letter-writing provided for trainees in Edinburgh, and there was a high degree of awareness of the implications of the Act in medical staff, our audit shows that the new legislation made no difference to letter-writing practices. The fear that the Act would reduce the information content or quality of written communications to GPs seems to have been unfounded, since we found no change in key items of information or letter length. Nevertheless, only two-thirds of necessary information was communicated, again indicating room for improvement. Psychiatrists had improved in providing explanations (formulations) of their patients' illnesses, but had become poorer in providing prognostic information. While letter length was unaffected by the Act or audit, letters written by SHOs or registrars continued to be lengthy (50\% more than one page in length), perhaps reflecting that they had yet to acquire skills in succinct communication.

Our audit activity, prompted by the Act, did result in less jargon and value judgements in psychiatrists' letters. The reduction in jargon is important if one considers the time implications of the Act's requirement to provide an adequate explanation of unintelligible terms; on the basis of our study, over $50 \%$ of the first year's letters contained jargon and would need to be explained to the lay person.

Our audit may have also assisted in reducing the use of value judgements. Initially over a quarter of psychiatrists' letters contained value judgements or personal comments, which were usually judged offensive, but with auditing, this was reduced to one in ten letters. The use of avoidable 'pejorative remarks', as well as the possibility of conveying the information inoffensively was recently explored by Crichton et al (1992) who reported that at least $80 \%$ of case-notes assessed "from cover to cover" contained "offensive pejorative remarks" which, in most cases, could be expressed in a more acceptable manner.

In addition, longer letters have a greater chance of containing pejorative comments. Since longer letters tended to be written by junior psychiatrists, it is possible that the risk of a letter being offensive depends both on the seniority of the letter's author, as well as its length.

A final concern about the Act was that considerable time may be required to separate information to which the patient may not have access. To address this issue, recent College guidelines have recommended written material be organised in such a manner to facilitate easy preparation of records. In Edinburgh, new case-note folders were issued for all patients on 1 November 1991, with a specific section for such information. Our results show that only 3\% of psychiatrists' letters contained such information, and that this tended to be clearly identified. It would seem that, in Edinburgh, the practice of clearly identifying third party information already existed prior to the Act.

\section{Conclusions}

Although medical personnel have felt the Act would have a positive effect on the quality of 
psychiatric notes (Butler \& Nicholls, 1993), our study shows that:

(a) the Access to Health Records Act has had no impact on the quality of written communication to GPs from psychiatrists,

(b) auditing such communications through hospital audit meetings can help make letters less potentially offensive and easier for the patient to understand.

SHOs and registrars write longer, and therefore potentially more insulting letters, but with experience, improvements can be seen.

The Appendix contains examples of comments we found which were likely to be offensive.

\section{Appendix}

\section{Definitions}

Letter structure The use of headings/paragraphs was noted. Length was measured for the main body of text in a letter.

Content The number of key items of information (Pullen \& Yellowlees, 1985) per letter was measured. They were:
(a) diagnosis
(b) treatment
(c) follow-up arrangements
(d) prognosis
(e) concise explanation of the condition.

Third party information This was defined as "information relating to, or provided by an individual, other than the patient, who could be identified by that information" (Access to Health Records Act, 1990).

Jargon "Terms which are not intelligible without explanation" (Access to Health Records Act, 1990).

Value judgements and personal comments Statements about the patient based on the psychiatrist's subjective personal opinions. This includes the "offensive pejorative comments" that the College guidelines (1993) recommend are avoided.

Some examples of terms or phrases regarded as jargon: (a) her affect was diurnal variation negative

(b) ...neurovegatative symptoms ...

(c) ....characterological problems. .

(d) ... cognition intact in all modalities. . .

(e) ... exhibited psycho-pervasive anhedonia...

(f) ... suffering an exaggerated grief reaction.

\section{Offensive remarks}

Some examples of potentially offensive remarks:

(a) the surgeon has not been impressed by her symptoms

(b) gives pathetic excuses for his behaviour

(c) the baby was conceived to keep the marriage together

(d) his coping skills leave a lot to be desired

(e) this girl (referring to married woman)

(f) an odd girl.

\section{References}

Access to Health Records Act 1990. HMSO.

BUTLER. R. E. \& NicHOus, D. E. (1993) The Access to Health Records Act: what difference does it make? Psychiatric Bulletin. 17. 204-206.

Crichton, P., Douzenis, A., LegGatt, C., et al (1992) Are psychiatric case-notes offenstve? Psychiatric Bulletin. 16. $675-677$.

DEPARTMENT OF HEALTH (1989) Working for Patients. Medical Audit. Working Paper 6. (Cmnd 555). London: HMSO.

MARGO. J. L. (1982) Letters from psychiatrists to general practitioners. Bulletin of the Royal College of Psychiatrists, 6, 139-141.

OPEN FORUM, EDUCATION COMMITTEE (1991) Medical audit: basic principles and current methods. Psychiatric Bulletin, 16, 21-25.

PRIEST, R. G. (1986) Data Protection Act: Subject to Personal Health Information (DA 8523): DHSS Consultation Paper. Psychiatric Bulletin. 16. 21-25.

PuLen, I. M. \& YeulowleEs, A. J. (1985) Is communication improving between general practitioners and psychiatrists? British Medical Journal, 280, 31-33.

Royal Coulege of PSYChIATRISTs (1992) Access to Health Records Act 1990. College guidance. Psychiatric Bulletin. 16. 114-116.

Yellowlees A. J. \& PULLeN, I. M. (1984) Communication between psychiatrists and geneal practitioners - what sort of letter should psychiatrists write? Health Bulletin. 42. 285-296

Young, R. C. Jr., RACHAL, R. E. \& MORgan, A. L. (1991) Maximising communication skills in graduate and postgraduate health-care education through medical writing. Journal of the National Medical Association. 83. 691-696.

*Premal J. Shah, Registrar, Royal Edinburgh Hospital, 151 Morningside Place, Edinburgh, EHIO 5HF, and Ian Pullen, Consultant Psychiatrist, Dingleton Hospital, Melrose, Raxburghshire TD6 9HN

*Correspondence 